\title{
Serum Levels of Plasmalogens and Fatty Acid Metabolites Associate with Retinal Microangiopathy in Participants from the Finnish Diabetes Prevention Study
}

\author{
Vanessa Derenji de Mello ${ }^{1, *}$, Tuomas Selander ${ }^{2}$, Jaana Lindström ${ }^{3} \mathbb{D}$, Jaakko Tuomilehto ${ }^{3,4,5}$, Matti Uusitupa ${ }^{1}$ (D) \\ and Kai Kaarniranta 6,7 (D) \\ 1 Institute of Public Health and Clinical Nutrition, University of Eastern Finland, FI-70211 Kuopio, Finland; \\ Matti.Uusitupa@uef.fi \\ 2 Science Service Center, Kuopio University Hospital, FI-70029 Kuopio, Finland; Tuomas.Selander@kuh.fi \\ 3 Public Health Prevention Unit, Finnish Institute for Health and Welfare, FI-00271 Helsinki, Finland; \\ Jaana.Lindstrom@thl.fi (J.L.); Jaakko.Tuomilehto@thl.fi (J.T.) \\ 4 Department of Public Health, University of Helsinki, FI-00014 Helsinki, Finland \\ 5 Diabetes Research Group, King Abdulaziz University, Jeddah 21589, Saudi Arabia \\ 6 Department of Ophthalmology, Kuopio University Hospital, FI-70029 Kuopio, Finland; kai.kaarniranta@uef.fi \\ 7 Institute of Clinical Medicine, Faculty of Health Sciences, University of Eastern Finland, \\ FI-70211 Kuopio, Finland \\ * Correspondence: Vanessa.Laaksonen@uef.fi
}

\section{check for} updates

Citation: de Mello, V.D.; Selander, T.; Lindström, J.; Tuomilehto, J.; Uusitupa, M.; Kaarniranta, K. Serum Levels of Plasmalogens and Fatty Acid Metabolites Associate with Retinal Microangiopathy in Participants from the Finnish Diabetes Prevention Study. Nutrients 2021, 13, 4452. https://doi.org/ $10.3390 /$ nu13124452

Academic Editor: Hans Demmelmair

Received: 16 November 2021 Accepted: 9 December 2021 Published: 14 December 2021

Publisher's Note: MDPI stays neutral with regard to jurisdictional claims in published maps and institutional affiliations.

Copyright: (c) 2021 by the authors. Licensee MDPI, Basel, Switzerland. This article is an open access article distributed under the terms and conditions of the Creative Commons Attribution (CC BY) license (https:// creativecommons.org/licenses/by/ $4.0 /)$.

\begin{abstract}
Diabetic retinopathy (DR) is the most common microvascular complication of diabetes, and retinal microaneurysms (MA) are one of the first detected abnormalities associated with DR. We recently showed elevated serum triglyceride levels to be associated with the development of MA in the Finnish Diabetes Prevention Study (DPS). The purpose of this metabolomics study was to assess whether serum fatty acid (FA) composition, plasmalogens, and low-grade inflammation may enhance or decrease the risk of MA. Originally, the DPS included 522 individuals (mean 55 years old, range 40-64 years) with impaired glucose tolerance who were randomized into an intervention ( $n=265)$ or control group $(n=257)$. The intervention lasted for a median of four years (active period), after which annual follow-up visits were conducted. At least five years after stopping the intervention phase of DPS, participants classified as MA negative $(n=115)$ or MA positive $(n=51)$ were included in the current study. All these participants were free of diabetes at baseline (WHO 1985) and had high-sensitive C-reactive protein (hs-CRP), serum FA composition, and selected lipid metabolites measured during the active study period. Among the markers associated with MA, the serum plasmalogen dm16:0 ( $p=0.006)$, the saturated odd-chain FA 15.0 (pentadecanoic acid; $p=0.015)$, and omega-3 very long-chain FAs $(p<0.05)$ were associated with a decreased occurrence of MA. These associations were independent of study group and other risk factors. The association of high serum triglycerides with the MA occurrence was attenuated when these MA-associated serum lipid markers were considered. Our findings suggest that, in addition to n-3 FAs, odd-chain FA 15:0 and plasmalogen dm16:0 may contribute to a lower risk of MA in individuals with impaired glucose tolerance. These putative novel lipid biomarkers have an association with MA independently of triglyceride levels.
\end{abstract}

Keywords: diabetic nephropathy; plasmalogens; serum fatty acids; lifestyles

\section{Introduction}

Diabetic retinopathy (DR) is the most common microvascular complication of diabetes and the leading cause of blindness in working-aged people with diabetes $[1,2]$. Retinal microaneurysms are one of the first detected abnormalities in fundus examinations associated with DR. The long duration of diabetes, poor glycemic control, and presence of hypertension are the main risk factors of DR [3]. The clinical signs of DR are identical 
in both type 1 and type 2 diabetes mellitus (T2DM), which include the development of microaneurysms (MA) (focal outpouchings of the retinal vessels), telangiectatic vessels, hemorrhages, exudates, capillary closure, and retinal neovascularization [4]. Elevated serum cholesterol and triglyceride concentrations have been reported to be a risk factor for DR $[5,6]$, and it has been suggested that permeability changes in the retinal microvasculature result in extravascular accumulations of lipoprotein deposits with a consequent loss of function in the surrounding retinal cells [7]. High serum cholesterol and triglyceride concentrations are also associated with leaking MAs in diabetic macular edema that may lead to permanent visual loss [8]. Complexes of lipoproteins and macrophages are visualized in fundus photography as hard exudates suggesting that increased serum lipid levels are a risk factor for this advanced form of exudates and other macular complications in diabetes $[8,9]$.

During the early stages of diabetes, retinal changes are primarily monitored by regular fundus photograph examinations. The early recognition of diabetes and DR is important to prevent or slow down the progression of late complications [10]. We recently documented that a lifestyle intervention program to prevent T2DM decreased the risk of retinal MA in the intervention group of individuals with impaired glucose tolerance (IGT) at baseline [11]. In this same study, we reported that elevated serum triglycerides were associated with the development of early diabetic microangiopathy in the Finnish Diabetes Prevention Study (DPS) [11]. In the DPS, which recruited overweighed participants with IGT [12,13], a lower risk of developing T2DM was associated with better insulin sensitivity (IS) and preserved $\beta$-cell capacity, both of which were related to healthy lifestyles [14].

Among the factors underlying elevated serum triglycerides are lifestyle (diet and physical activity), obesity, and T2DM. It is well known that dietary factors, in particular omega-3 fatty acids (FAs), are involved in the metabolism of triglycerides, and that these FAs have also many other metabolic effects [15], which are probably more directly associated with the development of early microvascular abnormalities related to diabetes. Among these factors, plasmalogens, fatty acid composition of cell membranes, inflammation, and oxidative stress could also be involved in the pathophysiological processes leading to early DR [16-21].

The association between dyslipidemia and DR has been extensively investigated, but a conclusive link or causality remains elusive. In the present study, we investigated putative underlying lipid-related factors that could explain the association of serum triglycerides with the development of early diabetic microangiopathy in a sub-group of participants of the Finnish DPS [11]. Specifically, the purpose of this metabolomics study was to assess whether serum FA composition, plasmalogens, and low-grade inflammation may enhance or decrease the risk of early DR.

\section{Materials and Methods}

\subsection{Participants and Study Design}

A total of 522 individuals with IGT at baseline (between 1993 and 1998) participated in the multicenter DPS randomized controlled trial study and were randomly assigned to the intensive lifestyle intervention or the control group [22]. The main goals of the lifestyle intervention delivered by clinical nutritionists were a reduction in body weight of $5 \%$ or more, total fat and saturated intakes less than $30 \%$ and $10 \%$ of energy consumed, respectively, fiber intake more than $15 \mathrm{~g} / 1000 \mathrm{kcal}$, and moderate physical activity of at least $30 \mathrm{~min} /$ day [23]. Detailed information of the study design and interventions has been presented previously $[12,23]$. All the participants were examined on a yearly basis for their fasting and $2 \mathrm{~h}$ glucose after an oral glucose tolerance test (OGTT), anthropometry, blood pressure, serum lipids, and several other parameters. The total time of the follow-up with intervention (median 4 years, range 1-6 years) and post-intervention period combined was up to 15 years [22], and 246 of the participants were diagnosed with T2DM during the total follow-up. Between the years 2002 and 2006 (at least five years after the intervention phase), the participants in four of the five study centers were invited to take part in the fundus 
photography examination (dilated pupils, one field 30-degree), as previously described, and this resulted in data being available for 201 participants [11]. Of those, 166 had serum lipid metabolomics measurements available for the present study. Therefore, participants (MA negative group: MA_neg, $n=115$; MA positive group: MA_pos, $n=51$ ) analyzed in this report include those who did not have diabetes according to the revised WHO 1999 criteria at baseline and had stored serum samples available from the active study period for serum FA composition and selected metabolites measurements (Table 1). According to what has been previously published, the intervention group had less frequent MAs $(24 \%$, $p=0.029$ ) compared with the control group (38\%) [11]. Otherwise, there were no significant differences in the incidence of early retinal changes identified from ocular photographs between the control and intervention groups, as in [11].

Table 1. Characteristics of the participants.

\begin{tabular}{cccc}
\hline & MA Neg & MA Pos & $p$-Value \\
\hline$n$ & 115 & 51 & \\
Study group, $n$ (I/C) & $67 / 48$ & $21 / 30$ & 0.062 \\
Sex, $n$ (men/women) & $35 / 80$ & $9 / 42$ & 0.126 \\
Age, years & $54.4 \pm 7.5$ & $52.0 \pm 6.2$ & 0.036 \\
BMI, kg/m ${ }^{2}$ & $31.3 \pm 5.0$ & $31.7 \pm 5.1$ & 0.641 \\
Triglycerides, mmol/L & $1.60 \pm 0.68$ & $1.85 \pm 0.68$ & 0.035 \\
HbA1c, \% & $5.53 \pm 0.56$ & $5.35 \pm 0.55$ & 0.051 \\
Hs-CRP, mg/L & $0.74 \pm 0.99$ & $0.68 \pm 1.01$ & 0.739 \\
\hline
\end{tabular}

MA: microangiopathy neg: negative pos: positive. I: intervention. C: control. Hs-CRP: high-sensitive Creactive protein.

\subsection{Biochemical Analyses}

Plasma glucose and serum insulin levels were determined as previously described [14]. High-sensitive C-reactive protein (hs-CRP) was measured in fasting serum at a one-year follow-up examination and thereafter yearly during the mean four-year intervention (active study) period using an IMMULITE ${ }^{\circledR} 2000$ Systems Analyzer (Siemens Healthcare Diagnostics, Inc. Tarrytown, NY, USA) [24,25].

The total serum FA composition and fatty acid metabolites (plasmalogens) were measured by gas chromatography using stored $-80^{\circ} \mathrm{C}$ serum samples taken during the active intervention period, as previously described [26]. The proportions of each of the FAs are expressed as molar percentages. The plasmalogens covered and detected by the applied method are the plasmalogen palmitic ( $\mathrm{dm} 16: 0)$ and plasmalogen stearic $(\mathrm{dm} 18: 0)$. The intra- and inter-assay CV \% for individual FAs and FA metabolites were $\leq 10 \%$ and $\leq 12 \%$, respectively.

Stearoyl-coenzyme A desaturases-1 and -2 (SCD-1, SCD-2) and delta 5 and 6 desaturase enzymes (D5D and D6D), the latter of which are suggested to predict the incidence of T2DM and may be involved in the development of T2DM [27-33], were estimated as follows: SCD-1 and SCD-2 activities as the product-to-precursor ratio of 16:1n-7/16:0 and 18:1n-9/18:0, respectively; and D5D and D6D activities by product-to-precursor ratios of 20:4n-6/20:3n-6 and 18:3n-6/18:2n-6, respectively.

\subsection{Statistical Methods}

Data for investigated variables from the first two years of the trial were averaged and these averaged data were expressed as means with standard deviations for both MA (yes = positive: pos/no = negative: neg) groups. Group difference in years 1 and 2 between these MA groups were compared by a linear mixed effect (LME) model for repeated measurements adjusted for study group. In full-adjusted LME analysis, we also included in the model BMI, HbA1c, age, sex, and either fasting triglycerides or hs-CRP levels. Beta coefficients and Z-scores with $95 \%$ confidence intervals (CI) were extracted from LME model for each marker to measure the adjusted group difference between MA groups during the first two years. Statistical analyses were executed by $\mathrm{R}$ statistical 
software, version 4.0.4 (R Foundation for Statistical Computing, Vienna, Austria). Twosided $p$-values $<0.05$ were set to indicate statistically significant results.

\section{Results}

\subsection{Serum FAs and Plasmalogens Relate with the Occurrence of MA Independently of the Study Group}

Among the FAs and their metabolites analyzed and illustrated in Table 2, we first applied simple statistical models, adjusting only for the study group. While the serum proportion of the odd-chain saturated FA 15:0 (pentadecanoic acid; $p=0.015$ ) was inversely associated with MA, the monounsaturated FAs (MUFAs) 16:1n-7 (palmitoleic acid; $p=0.026$ ), $18: 1 n-9$ (oleic acid; $p<0.001$ ), and 20:3n-9 (mead acid; $p=0.013$ ) were directly associated with the occurrence of MA (Table 2).

Table 2. Serum fatty acids, plasmalogens metabolites and estimated desaturases according to the occurrence of retinal microangiopathy (MA), and associations of MA with the serum fatty acids, plasmalogens metabolites and estimated desaturases.

\begin{tabular}{|c|c|c|c|c|c|}
\hline Serum Lipid Marker & MA Pos $^{1}$ & MA Neg $^{1}$ & & & \\
\hline $\mathrm{mmol} \%$ & Mean \pm SD & Mean \pm SD & $\beta$ Value & CI & $p^{2}$ \\
\hline 14:0 myristic & $1.5 \pm 0.45$ & $1.41 \pm 0.49$ & 0.04 & $-0.10 ; 0.18$ & 0.58 \\
\hline 15:0 pentadecanoic & $0.26 \pm 0.06$ & $0.28 \pm 0.07$ & -0.03 & $-0.05 ;-0.01$ & 0.015 \\
\hline 16:0 palmitic & $23.85 \pm 1.91$ & $23.36 \pm 1.85$ & 0.34 & $-0.23 ; 0.91$ & 0.25 \\
\hline 18:0 stearic & $6.84 \pm 0.71$ & $6.79 \pm 0.7$ & 0.06 & $-0.15 ; 0.27$ & 0.58 \\
\hline 20:0 arachidic & $0.11 \pm 0.03$ & $0.12 \pm 0.04$ & 0.00 & $-0.02 ; 0.01$ & 0.50 \\
\hline 22:0 behenic & $0.19 \pm 0.07$ & $0.19 \pm 0.07$ & 0.00 & $-0.02 ; 0.02$ & 0.92 \\
\hline 24:0 lignoceric & $0.17 \pm 0.07$ & $0.17 \pm 0.06$ & 0.00 & $-0.02 ; 0.02$ & 0.69 \\
\hline $14: 1 n-5$ myristoleate & $0.14 \pm 0.07$ & $0.13 \pm 0.07$ & 0.01 & $-0.01 ; 0.03$ & 0.56 \\
\hline $16: 1 n-7$ palmitoleic & $3.27 \pm 1.03$ & $2.88 \pm 0.96$ & 0.35 & $0.04 ; 0.66$ & 0.026 \\
\hline 18:1n-7 vaccenic & $1.63 \pm 0.53$ & $1.64 \pm 0.26$ & 0.00 & $-0.10 ; 0.10$ & 0.95 \\
\hline 18:1n-9 oleic & $21.94 \pm 1.9$ & $20.75 \pm 2.01$ & 1.16 & $0.54 ; 1.78$ & $<0.001$ \\
\hline 20:1n-9 gondoic & $0.23 \pm 0.08$ & $0.21 \pm 0.08$ & 0.02 & $0.00 ; 0.04$ & 0.11 \\
\hline 20:3n-9 mead & $0.15 \pm 0.06$ & $0.13 \pm 0.05$ & 0.02 & $0.00 ; 0.04$ & 0.013 \\
\hline 22:1n-9 erucic & $0.05 \pm 0.06$ & $0.04 \pm 0.04$ & 0.01 & $-0.01 ; 0.02$ & 0.41 \\
\hline $24: 1 n-9$ nervonic & $0.4 \pm 0.41$ & $0.35 \pm 0.16$ & 0.05 & $-0.02 ; 0.12$ & 0.19 \\
\hline 18:2n-6 linoleic & $24.6 \pm 3.75$ & $25.85 \pm 3.78$ & -0.95 & $-2.12 ; 0.21$ & 0.11 \\
\hline 18:3n-6 $\gamma$-linolenic & $0.4 \pm 0.15$ & $0.38 \pm 0.15$ & 0.02 & $-0.03 ; 0.06$ & 0.48 \\
\hline 20:2n-6 eicosadienoic & $0.3 \pm 0.09$ & $0.27 \pm 0.08$ & 0.03 & $0.01 ; 0.05$ & 0.01 \\
\hline $20: 3 n-6$ dihomo- $\gamma$-linolenic & $1.5 \pm 0.3$ & $1.44 \pm 0.31$ & 0.06 & $-0.03 ; 0.16$ & 0.20 \\
\hline 20:4n-6 arachidonic & $5.18 \pm 1.03$ & $5.42 \pm 1.02$ & -0.24 & $-0.55 ; 0.07$ & 0.13 \\
\hline $22: 2 n-6$ docosadienoic & $0.01 \pm 0.02$ & $0.01 \pm 0.01$ & 0.00 & $0.00 ; 0.01$ & 0.12 \\
\hline 22:4n-6 adrenic & $0.13 \pm 0.05$ & $0.13 \pm 0.04$ & 0.01 & $-0.01 ; 0.02$ & 0.30 \\
\hline 22:5n-6 osbond & $0.09 \pm 0.05$ & $0.09 \pm 0.03$ & 0.01 & $-0.01 ; 0.02$ & 0.31 \\
\hline 18:3n-3 đ-linolenic & $1.08 \pm 0.31$ & $1.03 \pm 0.26$ & 0.05 & $-0.03 ; 0.13$ & 0.20 \\
\hline 18:4n-3 stearidonic & $0.05 \pm 0.02$ & $0.05 \pm 0.03$ & 0.00 & $-0.01 ; 0.01$ & 0.68 \\
\hline $20: 4 n-3$ eicosatetraenoic & $0.2 \pm 0.08$ & $0.2 \pm 0.08$ & 0.00 & $-0.02 ; 0.03$ & 0.77 \\
\hline 20:5n-3 eicosapentaenoic & $1.37 \pm 0.59$ & $1.75 \pm 1$ & -0.42 & $-0.70 ;-0.14$ & 0.003 \\
\hline $22: 5 n-3$ docosapentaenoic & $0.59 \pm 0.17$ & $0.65 \pm 0.15$ & -0.06 & $-0.10 ;-0.01$ & 0.018 \\
\hline 22:6n-3 docosahexaenoic & $2.69 \pm 0.74$ & $3.18 \pm 1.1$ & -0.50 & $-0.82 ;-0.19$ & 0.002 \\
\hline $\operatorname{dm} 16: 0$ & $0.29 \pm 0.08$ & $0.33 \pm 0.09$ & -0.04 & $-0.06 ;-0.01$ & 0.006 \\
\hline $\mathrm{dm} 18: 0$ & $0.17 \pm 0.07$ & $0.19 \pm 0.08$ & -0.02 & $-0.05 ; 0.00$ & 0.044 \\
\hline $\mathrm{t} 16: 1 n-7$ & $0.15 \pm 0.05$ & $0.16 \pm 0.06$ & -0.01 & $-0.03 ; 0.00$ & 0.13 \\
\hline $\mathrm{t} 18: 1 n-9$ & $0.49 \pm 0.21$ & $0.45 \pm 0.19$ & 0.04 & $-0.02 ; 0.10$ & 0.17 \\
\hline SCD-1 ${ }^{3}$ & $13.58 \pm 3.56$ & $12.23 \pm 3.67$ & 1.26 & $0.11 ; 2.41$ & 0.032 \\
\hline SCD-2 ${ }^{3}$ & $24.12 \pm 9.01$ & $24.54 \pm 5.2$ & -0.23 & $-2.02 ; 1.57$ & 0.81 \\
\hline $\mathrm{D}^{2} \mathrm{D}^{3}$ & $3.56 \pm 0.90$ & $3.96 \pm 1.25$ & -0.42 & $-0.77 ;-0.07$ & 0.021 \\
\hline D6D $^{3}$ & $1.7 \pm 0.77$ & $1.53 \pm 0.7$ & 0.14 & $-0.08 ; 0.35$ & 0.21 \\
\hline
\end{tabular}

${ }^{1}$ mean values sampled at year 1 and 2 of the active trial period. ${ }^{2}$ linear mixed effect (LME) model for repeated measurements adjusted for study group. dm: plasmalogen. $\mathrm{t}$ : trans. ${ }^{3}$ expressed as ratios. SCD-1: Stearoylcoenzyme A desaturase 1. SCD-2: Stearoyl-coenzyme A desaturase 2. D5D: delta 5 desaturase enzyme. D6D: delta 5 desaturase enzyme.

Among the polyunsaturated FAs, 20:2n-6 (eicosadienoic acid; $p=0.01$ ) was higher in the MA_pos group while all 20:5n-3 (eicosapentaenoic acid; $p=0.030$ ), 22:5n-3 (docosapentaenoic acid; $p=0.018$ ), and 22:6n-3 (docosahexaenoic acid; $p=0.002)$ were lower in the 
MA_pos group (Table 2). D5D ( $p=0.021)$, but not D6D $(p=0.21)$, which was inversely associated with occurrence of MA (Table 2).

Even though only odd-chain 15:0 out of the saturated FA proportions associated with the occurrence of MA, the SCD-1 estimate $(p=0.032)$ was also significantly but directly associated with the presence of MA, but not SCD-2 $(p=0.806)$ (Table 2). Of note, serum plasmalogens $\operatorname{dm} 16: 0(p=0.006)$ and $\operatorname{dm} 18: 0(p=0.044)$ were both inversely associated with the occurrence of MA (Table 2).

In the full-adjusted models (Figure 1), the associations remained unchanged for the FAs, estimated desaturases and dm16:0, except for both SCD-1 $(p=0.074)$ and dm18:0 $(p=0.103)$, which lost their significance in relation to MA occurrence.

$\begin{array}{lcc}\text { Marker } & \text { MA pos } & \text { MA neg } \\ 14: 0 & 1.50(0.45) & 1.41(0.49) \\ 15: 0 & 0.26(0.06) & 0.28(0.07) \\ 16: 0 & 23.85(1.91) & 23.36(1.85) \\ 18: 0 & 6.84(0.71) & 6.79(0.70) \\ 20: 0 & 0.11(0.03) & 0.12(0.04) \\ 22: 0 & 0.19(0.07) & 0.19(0.07) \\ 24: 0 & 0.17(0.07) & 0.17(0.06) \\ 14: 1 \mathrm{n}-5 & 0.14(0.07) & 0.13(0.07) \\ 16: 1 \mathrm{n}-7 & 3.27(1.03) & 2.88(0.96) \\ 18: 1 \mathrm{n}-7 & 1.63(0.53) & 1.64(0.26) \\ 18: 1 \mathrm{n}-9 & 21.94(1.90) & 20.75(2.01) \\ 20: 1 \mathrm{n}-9 & 0.23(0.08) & 0.21(0.08) \\ 20: 3 \mathrm{n}-9 & 0.15(0.06) & 0.13(0.05) \\ 22: 1 \mathrm{n}-9 & 0.05(0.06) & 0.04(0.04) \\ 24: 1 \mathrm{n}-9 & 0.40(0.41) & 0.35(0.16) \\ 18: 2 \mathrm{n}-6 & 24.60(3.75) & 25.85(3.78) \\ 18: 3 \mathrm{n}-6 & 0.40(0.15) & 0.38(0.15) \\ 20: 2 \mathrm{n}-6 & 0.30(0.09) & 0.27(0.08) \\ 20: 3 \mathrm{n}-6 & 1.50(0.30) & 1.44(0.31) \\ 20: 4 \mathrm{n}-6 & 5.18(1.03) & 5.42(1.02) \\ 22: 2 \mathrm{n}-6 & 0.01(0.02) & 0.01(0.01) \\ 22: 4 \mathrm{n}-6 & 0.13(0.05) & 0.13(0.04) \\ 22: 5 \mathrm{n}-6 & 0.09(0.05) & 0.09(0.03) \\ 18: 3 \mathrm{n}-3 & 1.08(0.31) & 1.03(0.26) \\ 18: 4 \mathrm{n}-3 & 0.05(0.02) & 0.05(0.03) \\ 20: 4 \mathrm{n}-3 & 0.20(0.08) & 0.20(0.08) \\ 20: 5 \mathrm{n}-3 & 1.37(0.59) & 1.75(1.00) \\ 22: 5 \mathrm{n}-3 & 0.59(0.17) & 0.65(0.15) \\ 22: 6 \mathrm{n}-3 & 2.69(0.74) & 3.18(1.10) \\ \mathrm{dm} 16: 0 & 0.29(0.08) & 0.33(0.09) \\ \mathrm{dm} 18: 0 & 0.17(0.07) & 0.19(0.08) \\ \mathrm{t} 16: 1 \mathrm{n}-7 & 0.15(0.05) & 0.16(0.06) \\ \mathrm{t} 18: 1 \mathrm{n}-9 & 0.49(0.21) & 0.45(0.19) \\ \mathrm{SCD}-1 & 13.58(3.56) & 12.23(3.67) \\ \mathrm{SCD}-2 & 24.12(9.01) & 24.54(5.20) \\ \mathrm{D} 6 \mathrm{D} & 1.70(0.77) & 1.53(0.70) \\ \mathrm{D} 5 \mathrm{D} & 3.56(0.90) & 3.96(1.25) \\ & & \\ & & \\ & & \end{array}$
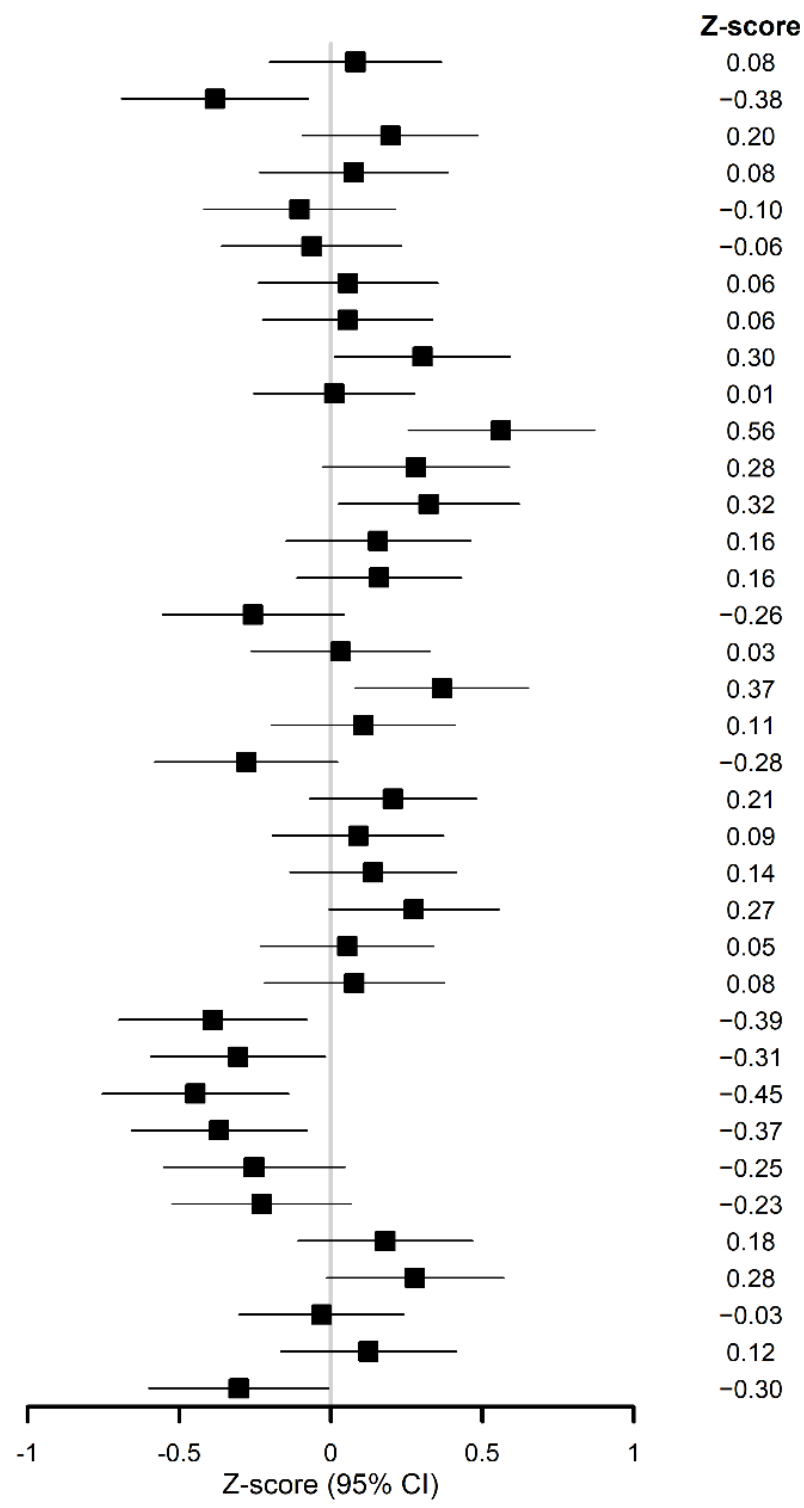

Figure 1. Z-scores for serum lipid metabolite markers and their standard deviations (SD) in the forest plot describing the association of each serum lipid metabolite markers with the occurrence of microaneurysms after applying full-adjusted linear mixed effect (LME) model for repeated measurements adjusted for study group, BMI, HbA1c, age, sex and fasting serum triglycerides. dm: plasmalogen; t: trans; SCD-1: Stearoyl-coenzyme A desaturase 1; SCD-2: Stearoyl-coenzyme A desaturase 2; D5D: delta 5 desaturase enzyme; D6D: delta 5 desaturase enzyme. 


\subsection{MA-Associated Metabolites Attenuate the Relationship of Serum Triglycerides with MA Occurrence}

Applying full-adjusted models, the previously observed direct association of serum triglycerides levels with MA, suggesting the harmful effect on the development of MA [11], was either attenuated or completely lost when adjusted for the FAs, plasmalogens, or calculated desaturase activities that we found to be associated with the presence of MA (Table 3).

Table 3. Association strength ( $\beta$ and $C I$ ) of serum triglycerides levels with MA, when MA-associated lipid metabolite markers were included in the model.

\begin{tabular}{cccc}
\hline $\begin{array}{c}\text { Serum Lipid Marker Included in } \\
\text { the Model }{ }^{\mathbf{1}}\end{array}$ & $\begin{array}{c}\text { Triglyceride's } \\
\text { Resulting } \boldsymbol{\beta} \text { Value }\end{array}$ & CI & $\boldsymbol{p}^{\mathbf{1}}$ \\
\hline $15: 0$ & 0.16 & $(-0.02 ; 0.34)$ & 0.09 \\
$16: 1 n-7$ & 0.10 & $(-0.07 ; 0.27)$ & 0.24 \\
$18: 1 n-9$ & 0.03 & $(-0.12 ; 0.18)$ & 0.68 \\
$20: 5 n-3$ & 0.13 & $(-0.04 ; 0.31)$ & 0.14 \\
$22: 5 n-3$ & 0.16 & $(-0.02 ; 0.34)$ & 0.09 \\
$22: 6 n-3$ & 0.13 & $(-0.04 ; 0.31)$ & 0.14 \\
dm16:0 & 0.06 & $(-0.09 ; 0.21)$ & 0.41 \\
\hline
\end{tabular}

1 each marker was included one by one as a covariate in the linear mixed effect (LME) model for repeated measurements in addition to study group, BMI, HbA1c, age, sex and serum fasting triglycerides. dm: plasmalogen.

\subsection{Low-Grade Inflammation Is Not Associated with the Occurrence of $M A$}

We did not find any significant association of hsCRP with MA in either of these models (simple, $p=0.87$; full-adjusted, $p=0.704$ ). The associations found for FA proportions, plasmalogens, or desaturases with the presence of MA were independent of hsCRP (Table 4).

Table 4. Association of serum fatty acids, plasmalogens metabolites and estimated desaturases with the presence of retinal microangiopathy (MA) in full-adjusted models.

\begin{tabular}{|c|c|c|c|}
\hline Serum Lipid Marker & $\beta$ & CI & $p^{1}$ \\
\hline 14:0 myristic & 0.04 & $-0.10 ; 0.17$ & 0.573 \\
\hline 15:0 pentadecanoic & -0.03 & $-0.05 ; 0.00$ & 0.016 \\
\hline 16:0 palmitic & 0.37 & $-0.17 ; 0.92$ & 0.184 \\
\hline 18:0 stearic & 0.05 & $-0.16 ; 0.27$ & 0.630 \\
\hline 20:0 arachidic & 0.00 & $-0.02 ; 0.01$ & 0.521 \\
\hline 22:0 behenic & 0.00 & $-0.03 ; 0.02$ & 0.675 \\
\hline 24:0 lignoceric & 0.00 & $-0.02 ; 0.02$ & 0.705 \\
\hline $14: 1 n-5$ myristoleate & 0.00 & $-0.02 ; 0.02$ & 0.698 \\
\hline $16: 1 n-7$ palmitoleic & 0.30 & $0.01 ; 0.59$ & 0.042 \\
\hline 18:1n-7 vaccenic & 0.00 & $-0.09 ; 0.10$ & 0.930 \\
\hline 18:1n-9 oleic & 1.16 & $0.53 ; 1.79$ & $<0.001$ \\
\hline $20: 1 n-9$ gondoic & 0.02 & $0.00 ; 0.05$ & 0.075 \\
\hline 20:3n-9 mead & 0.02 & $0.00 ; 0.03$ & 0.035 \\
\hline 22:1n-9 erucic & 0.01 & $-0.01 ; 0.02$ & 0.317 \\
\hline 24:1n-9 nervonic & 0.04 & $-0.03 ; 0.12$ & 0.250 \\
\hline 18:2n-6 linoleic & -0.98 & $-2.12 ; 0.16$ & 0.094 \\
\hline 18:3n-6 $\gamma$-linolenic & 0.00 & $-0.04 ; 0.05$ & 0.827 \\
\hline 20:2n-6 eicosadienoic & 0.03 & $0.01 ; 0.06$ & 0.012 \\
\hline 20:3n-6 dihomo- $\gamma$-linolenic & 0.03 & $-0.06 ; 0.13$ & 0.485 \\
\hline 20:4n-6 arachidonic & -0.29 & $-0.60 ; 0.02$ & 0.070 \\
\hline $22: 2 n-6$ docosadienoic & 0.00 & $0.00 ; 0.01$ & 0.147 \\
\hline 22:4n-6 adrenic & 0.00 & $-0.01 ; 0.02$ & 0.529 \\
\hline $22: 5 n-6$ osbond & 0.01 & $-0.01 ; 0.02$ & 0.321 \\
\hline
\end{tabular}


Table 4. Cont.

\begin{tabular}{cccc}
\hline Serum Lipid Marker & $\boldsymbol{\beta}$ & $\mathbf{C I}$ & $\boldsymbol{p}^{\mathbf{1}}$ \\
\hline 18:3n-3 a-linolenic & 0.08 & $0.00 ; 0.15$ & 0.056 \\
18:4n-3 stearidonic & 0.00 & $-0.01 ; 0.01$ & 0.709 \\
20:4n-3 eicosatetraenoic & 0.01 & $-0.02 ; 0.03$ & 0.608 \\
20:5n-3 eicosapentaenoic & -0.35 & $-0.63 ;-0.07$ & 0.015 \\
22:5n-3 docosapentaenoic & -0.05 & $-0.09 ; 0.00$ & 0.039 \\
22:6n-3 docosahexaenoic & -0.46 & $-0.77 ;-0.14$ & 0.005 \\
dm16:0 & -0.03 & $-0.06 ;-0.01$ & 0.013 \\
dm18:0 & -0.02 & $-0.04 ; 0.00$ & 0.099 \\
t16:1n-7 & -0.01 & $-0.03 ; 0.00$ & 0.132 \\
t18:1n-9 & 0.04 & $-0.02 ; 0.09$ & 0.223 \\
SCD-1 & 1.02 & $-0.05 ; 2.10$ & 0.064 \\
SCD-2 & -0.21 & $-2.04 ; 1.63$ & 0.825 \\
D5D & -0.35 & $-0.70 ;-0.01$ & 0.046 \\
D6D & 0.09 & $-0.12 ; 0.30$ & 0.400 \\
\hline
\end{tabular}

$\overline{1}$ each marker was included one by one as a covariate in the linear mixed effect (LME) model for repeated measurements in addition to study group, $\mathrm{BMI}, \mathrm{HbA1c}$, age, sex and serum high-sensitive C-reactive protein. SCD-1: Stearoyl-coenzyme A desaturase 1. SCD-2: Stearoyl-coenzyme A desaturase 2. D5D: delta 5 desaturase enzyme. D6D: delta 5 desaturase enzyme.

\section{Discussion}

We found that serum plasmalogens, particularly the one with palmitic acid in its structure, together with saturated odd-chain FA 15.0 (pentadecanoic acid) and omega-3 very long-chain FAs were associated with decreased occurrence of MA. Conversely, MUFAs were associated with an increased the occurrence of MA.

Plasmalogens represent an important class of phospholipids whose presence is required for proper brain and eye development [34]. In adults at high risk of developing T2DM, the plasmalogens containing palmitic acid in their structure were found to be increased as a result of an 18-24-week Nordic healthy diet. This Nordic diet was rich in whole grains, fruits, vegetables, berries, vegetable fat, and fish, along with low-fat milk products and low-fat meat choices [35]. Other plasmalogens species are also among the serum metabolites associated with higher nut intake in adults without T2DM [36]. Therefore, increased levels of these lipid metabolites in participants who did not have MA could be partly associated with the protective effects of a healthy diet. Plasmalogens form a specific subclass of glycerophospholipids characterized by the presence of a vinyl-ether bond at the sn-1 position of the glycerol backbone, instead of an ester bond, as seen in diacyl-glycerophospholipids. Plasmalogens have antioxidative potential [37] and increased lipid oxidation is linked to decreased plasmalogen concentrations [18]. Lipid oxidation is in turn related to the development and progression of DR [38,39]. In the eye, plasmalogens account for $30 \%$ of glycerolphosphatidyletanolamines in retinal pigment epithelial cells that are highly exposed to oxidative damage. In these cells, plasmalogens have been suggested to play protective roles against oxidative stress [34].

We observed that the odd-chain FA 15:0 (pentadecanoic acid) and omega-3 very longchain FAs were associated with a decreased occurrence of MA (Figure 2). Oxidative stress and inflammation have been proven to be critical contributors to the development of DR $[39,40]$. It has been reported that in vivo oxidative stress measured in plasma and urine from patients with T2DM was reduced by the supplementation of $n-3$ FAs [41]. Overall, data coming from human and animal studies suggest $n-3$ FAs in the prevention and treatment of retinal diseases due to their effects on improving retinal oxidative stress and inflammation [42]. Although we were not able to directly link lower systemic inflammation with less occurrence of MA, we cannot rule out an anti-inflammatory effect on the retina of higher $n-3$ and 15:0 FAs. In some studies, a beneficial effect of sources of $n-3$ FAs on risk markers of T2DM $[43,44]$ and a possible protective effect of these FAs on the prevalence and progression of diabetic MA have also been shown [45]. We have previously found that MA occurrence was lower in a subpopulation of the DPS allocated to the lifestyle 
intervention group [11]. Therefore, the relationship of lifestyle changes with healthier eyes in the long term could be explained by dietary changes that are involved in protective biochemical pathways that may prevent later DR development. n-3 long-chain FAs also predicted a decreased risk of T2DM in the DPS [26] and this was confirmed in a recent meta-analysis [46]. The odd chain 15:0 FA may be derived from milk fat, but also, e.g., from fish, whereas the role of gut microbiota after dietary interventions rich in fiber intake in its formation is not yet fully understood [47-50]. Nevertheless, high fiber intake has been associated with a lower risk of developing T2DM $[49,51]$, which may be associated with other healthy aspects of a higher fiber intake.

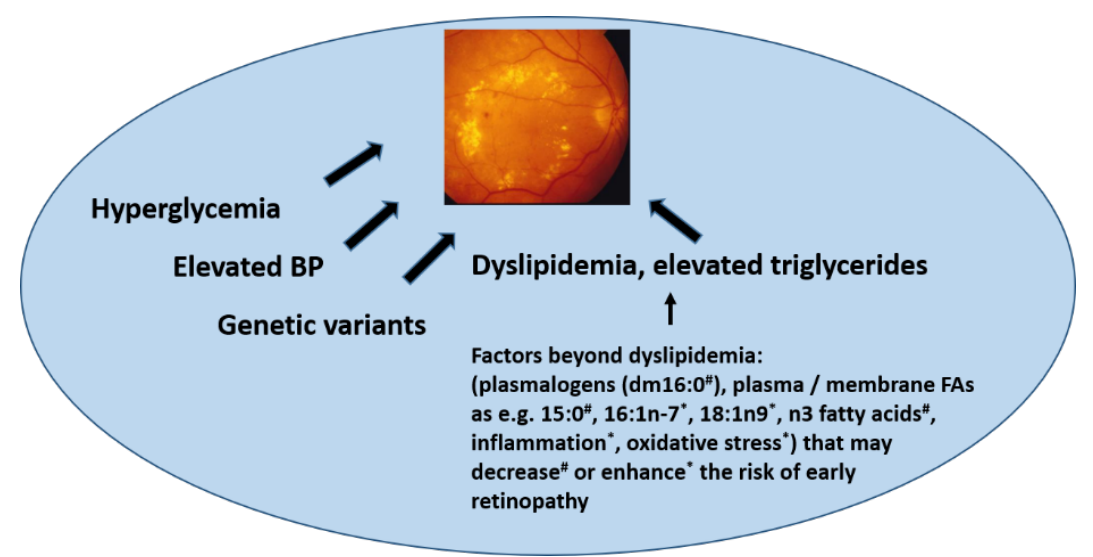

Figure 2. Factors associated with the development of retinopathy. BP: blood pressure FA: fatty acids. With symbols are the proposed factors we find associated with retinal microaneurysms occurrence in the present study (\# positively associated; * negatively associated).

The increased occurrence of MA with MUFAs might be attributed to its possible proangiogenic role of in retina [52,53]. Nevertheless, inverse associations have been observed between total MUFAs and oleic acid intakes with DR, in persons with T2DM [54]. Our results related to MUFA in blood do not necessarily reflect their dietary intake, but rather metabolic disturbances, e.g., as in $[55,56]$. In the typical Finnish diet, the main source of oleic acid is milk fat that is rich in oleic acid (about 25\%) [57].

Strengths of the present study include the well-characterized and homogenous study population comprising overweight and obese people with IGT. The outcome, MA, was determined without information concerning any metabolic parameters. The major limitation in our study is that we do not have baseline data on retinal changes. We also did not perform fundus photography examination in all of the DPS participants. However, the overall results retrieved from this study are plausible and thus add to the scientific field of pathophysiology and prevention of DR in T2DM.

Our findings support the view that dyslipidemia and specific lipid metabolites, in addition to high serum triglycerides, play an important pathogenic role in the development of DR. The benefit of $n$-3-long chain FAs and C15:0 for eye health has also been related to a decreased risk of T2DM.

\section{Conclusions}

In conclusion, here, we show putative novel lipid biomarkers beyond serum triglycerides that are associated with MA. Our new findings suggest that plasmalogen dm16:0 may contribute to a lower risk of MA in overweight and obese individuals with IGT, especially in those who have elevated serum triglycerides. Our observation may open new lines of lipid-lowering therapies in future investigations aiming at preventing retinal complications in persons with hyperglycemia. In Figure 2, we propose to include the present findings among the factors beyond dyslipidemia that may enhance or decrease the risk of early nephropathy. 
Author Contributions: J.L., J.T. and M.U. contributed to the study design, acquisition of data and funding. T.S. performed the statistical analyses. V.D.d.M. participated in the interpretation of the data and V.D.d.M. drafted the article. M.U. and K.K. contributed to supervising the data analysis. All the authors have critically contributed to the manuscript, approved the final version, and take responsibility for the integrity of the data and the accuracy of the data analysis. All authors have read and agreed to the published version of the manuscript.

Funding: This research was funded by Academy of Finland $(296840,333302)$, the Kuopio University Hospital VTR grant (5503743), the Sigrid Juselius Foundation, the Päivikki and Sakari Sohlberg Foundation, and the University of Eastern Finland strategical support the Finnish Eye Foundation.

Institutional Review Board Statement: The study design and procedures of the study were carried out in accordance with the principles of the Declaration of Helsinki and was approved by the Ethics Committee of the National Public Health Institute of Helsinki, Finland in 6 March 1992.

Informed Consent Statement: Informed consent was obtained from all subjects involved in the study.

Conflicts of Interest: The authors declare no conflict of interest.

\section{References}

1. Klein, R.; Klein, B.E.; Moss, S.E.; Davis, M.D.; DeMets, D.L. The Wisconsin Epidemiologic Study of Diabetic Retinopathy. III. Prevalence and Risk of Diabetic Retinopathy when Age at Diagnosis is 30 or More Years. Arch. Ophthalmol. 1984, 102, 527-532. [CrossRef]

2. Klein, R.; Klein, B.E.K.; Moss, S.E. Epidemiology of Proliferative Diabetic Retinopathy. Diabetes Care 1992, 15, 1875-1891. [CrossRef] [PubMed]

3. Yau, J.W.Y.; Rogers, S.L.; Kawasaki, R.; Lamoureux, E.L.; Kowalski, J.W.; Bek, T.; Chen, S.-J.; Dekker, J.M.; Fletcher, A.; Grauslund, J.; et al. Global Prevalence and Major Risk Factors of Diabetic Retinopathy. Diabetes Care 2012, 35, 556-564. [CrossRef]

4. Das, R.; Kerr, R.; Chakravarthy, U.; Hogg, R.E. Dyslipidemia and Diabetic Macular Edema: A Systematic Review and MetaAnalysis. Ophthalmology 2015, 122, 1820-1827. [CrossRef] [PubMed]

5. Golubovic-Arsovska, M. Association of dyslipidaemia with macular oedema and hard exudates in diabetic maculopathy. Prilozi 2007, 28, 149-160. [PubMed]

6. Asensio-Sánchez, V.M.; Gómez-Ramírez, V.; Morales-Gómez, I.; Rodríguez-Vaca, I. Clinically Significant Diabetic Macular Edema: Systemic Risk Factors. Arch. Soc. Esp. Oftalmol. 2008, 83, 173-176. [CrossRef]

7. Diep, T.M.; Tsui, I. Risk factors associated with diabetic macular edema. Diabetes Res. Clin. Pract. 2013, 100, 298-305. [CrossRef]

8. Klein, B.E.; Moss, S.E.; Klein, R.; Surawicz, T.S. The Wisconsin Epidemiologic Study of Diabetic Retinopathy. XIII. Relationship of Serum Cholesterol to Retinopathy and Hard Exudate. Ophthalmology 1991, 98, 1261-1265. [CrossRef]

9. Chew, E.Y.; Klein, M.L.; Ferris, F.L., 3rd; Remaley, N.A.; Murphy, R.P.; Chantry, K.; Hoogwerf, B.J.; Miller, D. Association of Elevated Serum Lipid Levels with Retinal Hard Exudate in Diabetic Retinopathy. Early Treatment Diabetic Retinopathy Study (ETDRS) Report 22. Arch. Ophthalmol. 1996, 114, 1079-1084. [CrossRef]

10. Diabetes Prevention Program Research Group. Long-Term Effects of Lifestyle Intervention Or Metformin on Diabetes Development and Microvascular Complications Over 15-Year Follow-Up: The Diabetes Prevention Program Outcomes Study. Lancet Diabetes Endocrinol. 2015, 3, 866-875. [CrossRef]

11. Aro, A.; Kauppinen, A.; Summanen, P.; Kivinen, N.; Selander, T.; Kinnunen, K.; Tuomilehto, J.; Keinänen-Kiukaanniemi, S.; Lindström, J.; Uusitupa, M.; et al. Life Style Intervention Improves Retinopathy Status-The Finnish Diabetes Prevention Study. Nutrients 2019, 11, 1691. [CrossRef]

12. Tuomilehto, J.; Lindström, J.; Eriksson, J.G.; Valle, T.T.; Hämäläinen, H.; Ilanne-Parikka, P.; Keinänen-Kiukaanniemi, S.; Laakso, M.; Louheranta, A.; Rastas, M.; et al. Prevention of Type 2 Diabetes Mellitus by Changes in Lifestyle among Subjects with Impaired Glucose Tolerance. N. Engl. J. Med. 2001, 344, 1343-1350. [CrossRef] [PubMed]

13. Lindström, J.; Ilanne-Parikka, P.; Peltonen, M.; Aunola, S.; Eriksson, J.; Hemiö, K.; Hämäläinen, H.; Härkönen, P.; KeinänenKiukaanniemi, S.; Laakso, M.; et al. Sustained reduction in the incidence of type 2 diabetes by lifestyle intervention: Follow-up of the Finnish Diabetes Prevention Study. Lancet 2006, 368, 1673-1679. [CrossRef]

14. de Mello, V.D.; Lindström, J.; Eriksson, J.; Ilanne-Parikka, P.; Keinanen-Kiukaanniemi, S.; Sundvall, J.; Laakso, M.; Tuomilehto, J.; Uusitupa, M. Insulin Secretion and its Determinants in the Progression of Impaired Glucose Tolerance to Type 2 Diabetes in Impaired Glucose-Tolerant Individuals: The Finnish Diabetes Prevention Study. Diabetes Care 2012, 35, 211-217. [CrossRef]

15. Adkins, Y.; Kelley, D.S. Mechanisms underlying the cardioprotective effects of omega-3 polyunsaturated fatty acids. J. Nutr. Biochem. 2010, 21, 781-792. [CrossRef]

16. Kulacoglu, D.N.; Kocer, I.; Kurtul, N.; Keles, S.; Baykal, O. Alterations of fatty acid composition of erythrocyte membrane in type 2 diabetes patients with diabetic retinopathy. Jpn. J. Ophthalmol. 2003, 47, 551-556. [CrossRef] [PubMed]

17. Pietiläinen, K.H.; Sysi-Aho, M.; Rissanen, A.; Seppänen-Laakso, T.; Yki-Jarvinen, H.; Kaprio, J.; Oresic, M. Acquired Obesity is Associated with Changes in the Serum Lipidomic Profile Independent of Genetic Effects-A Monozygotic Twin Study. PLoS ONE 2007, 2, e218. [CrossRef] 
18. Braverman, N.E.; Moser, A.B. Functions of plasmalogen lipids in health and disease. Biochim. Biophys. Acta 2012, $1822,1442-1452$. [CrossRef] [PubMed]

19. Koehrer, P.; Saab, S.; Berdeaux, O.; Isaïco, R.; Grégoire, S.; Cabaret, S.; Bron, A.M.; Creuzot-Garcher, C.P.; Bretillon, L.; Acar, N. Erythrocyte Phospholipid and Polyunsaturated Fatty Acid Composition in Diabetic Retinopathy. PLoS ONE 2014,9 , e106912. [CrossRef]

20. Mason, R.P.; Libby, P.; Bhatt, D.L. Emerging Mechanisms of Cardiovascular Protection for the Omega-3 Fatty Acid Eicosapentaenoic Acid. Arter. Thromb. Vasc. Biol. 2020, 40, 1135-1147. [CrossRef]

21. Rivera, R.R.R.; Castellanos-González, J.A.; Montaño, C.O.; Flores-Martin, R.A.; Contreras, A.K.L.; Arevalo-Simental, D.E.; Cardona-Muñoz, E.G.; Roman-Pintos, L.M.; Rodríguez-Carrizalez, A.D. Adjuvant Therapies in Diabetic Retinopathy as an Early Approach to Delay Its Progression: The Importance of Oxidative Stress and Inflammation. Oxidative Med. Cell. Longev. 2020, 2020, 3096470. [CrossRef]

22. Lindström, J.; Peltonen, M.; Eriksson, J.G.; Ilanne-Parikka, P.; Aunola, S.; Keinänen-Kiukaanniemi, S.; Uusitupa, M.; Tuomilehto, J.; for the Finnish Diabetes Prevention Study (DPS). Improved lifestyle and decreased diabetes risk over 13 years: Long-term follow-up of the randomised Finnish Diabetes Prevention Study (DPS). Diabetologia 2013, 56, 284-293. [CrossRef]

23. Lindström, J.; Louheranta, A.; Mannelin, M.; Rastas, M.; Salminen, V.; Eriksson, J.; Uusitupa, M.; Tuomilehto, J. The Finnish Diabetes Prevention Study (DPS): Lifestyle intervention and 3-year results on diet and physical activity. Diabetes Care 2003, 26, 3230-3236. [CrossRef] [PubMed]

24. De Mello, V.D.; Paananen, J.; Lindström, J.; Lankinen, M.A.; Shi, L.; Kuusisto, J.; Pihlajamäki, J.; Auriola, S.; Lehtonen, M.; Rolandsson, O.; et al. Indolepropionic acid and novel lipid metabolites are associated with a lower risk of type 2 diabetes in the Finnish Diabetes Prevention Study. Sci. Rep. 2017, 7, 46337. [CrossRef]

25. Tuomainen, M.; Lindström, J.; Lehtonen, M.; Auriola, S.; Pihlajamäki, J.; Peltonen, M.; Tuomilehto, J.; Uusitupa, M.; De Mello, V.D.; Hanhineva, K. Associations of serum indolepropionic acid, a gut microbiota metabolite, with type 2 diabetes and low-grade inflammation in high-risk individuals. Nutr. Diabetes 2018, 8, 35. [CrossRef]

26. Takkunen, M.J.; Schwab, U.S.; de Mello, V.D.; Eriksson, J.G.; Lindström, J.; Tuomilehto, J.; Uusitupa, M.I.; DPS Study Group. Longitudinal Associations of Serum Fatty Acid Composition with Type 2 Diabetes Risk and Markers of Insulin Secretion and Sensitivity in the Finnish Diabetes Prevention Study. Eur. J. Nutr. 2016, 55, 967-979. [CrossRef]

27. Vessby, B.; Aro, A.; Skarfors, E.; Berglund, L.; Salminen, I.; Lithell, H. The Risk to Develop NIDDM is Related to the Fatty Acid Composition of the Serum Cholesterol Esters. Diabetes 1994, 43, 1353-1357. [CrossRef] [PubMed]

28. ARIC Study Investigators; Wang, L.; Folsom, A.R.; Zheng, Z.-J.; Pankow, J.S.; Eckfeldt, J.H. Plasma fatty acid composition and incidence of diabetes in middle-aged adults: The Atherosclerosis Risk in Communities (ARIC) Study. Am. J. Clin. Nutr. 2003, 78, 91-98. [CrossRef] [PubMed]

29. Krachler, B.; Norberg, M.; Eriksson, J.W.; Hallmans, G.; Johansson, I.; Vessby, B.; Weinehall, L.; Lindahl, B. Fatty acid profile of the erythrocyte membrane preceding development of Type 2 diabetes mellitus. Nutr. Metab. Cardiovasc. Dis. 2008, 18, 503-510. [CrossRef] [PubMed]

30. Djoussé, L.; Biggs, M.L.; Lemaitre, R.N.; King, I.B.; Song, X.; Ix, J.H.; Mukamal, K.J.; Siscovick, D.S.; Mozaffarian, D. Plasma omega-3 fatty acids and incident diabetes in older adults. Am. J. Clin. Nutr. 2011, 94, 527-533. [CrossRef]

31. Kröger, J.; Zietemann, V.; Enzenbach, C.; Weikert, C.; Jansen, E.H.; Döring, F.; Joost, H.-G.; Boeing, H.; Schulze, M.B. Erythrocyte membrane phospholipid fatty acids, desaturase activity, and dietary fatty acids in relation to risk of type 2 diabetes in the European Prospective Investigation into Cancer and Nutrition (EPIC)-Potsdam Study. Am. J. Clin. Nutr. 2011, 93, 127-142. [CrossRef]

32. Mahendran, Y.; Ågren, J.; Uusitupa, M.; Cederberg, H.; Vangipurapu, J.; Stančáková, A.; Schwab, U.; Kuusisto, J.; Laakso, M. Association of erythrocyte membrane fatty acids with changes in glycemia and risk of type 2 diabetes. Am. J. Clin. Nutr. 2013, 99, 79-85. [CrossRef] [PubMed]

33. Virtanen, J.K.; Mursu, J.; Voutilainen, S.; Uusitupa, M.; Tuomainen, T.-P. Serum Omega-3 Polyunsaturated Fatty Acids and Risk of Incident Type 2 Diabetes in Men: The Kuopio Ischemic Heart Disease Risk Factor Study. Diabetes Care 2014, 37, 189-196. [CrossRef] [PubMed]

34. Saab, S.; Mazzocco, J.; Creuzot-Garcher, C.P.; Bron, A.M.; Bretillon, L.; Acar, N. Plasmalogens in the retina: From occurrence in retinal cell membranes to potential involvement in pathophysiology of retinal diseases. Biochimie 2014, 107, 58-65. [CrossRef]

35. Lankinen, M.; Schwab, U.; Kolehmainen, M.; Paananen, J.; Nygren, H.; Seppänen-Laakso, T.; Poutanen, K.; Hyötyläinen, T.; Risérus, U.; Savolainen, M.J.; et al. A Healthy Nordic Diet Alters the Plasma Lipidomic Profile in Adults with Features of Metabolic Syndrome in a Multicenter Randomized Dietary Intervention. J. Nutr. 2015, 146, 662-672. [CrossRef] [PubMed]

36. Malik, V.S.; Guasch-Ferre, M.; Hu, F.B.; Townsend, M.K.; Zeleznik, O.A.; Eliassen, A.H.; Tworoger, S.S.; Karlson, E.W.; Costenbader, K.H.; Ascherio, A.; et al. Identification of Plasma Lipid Metabolites Associated with Nut Consumption in US Men and Women. J. Nutr. 2019, 149, 1215-1221. [CrossRef]

37. Broniec, A.; Klosinski, R.; Pawlak, A.; Wrona-Krol, M.; Thompson, D.; Sarna, T. Interactions of plasmalogens and their diacyl analogs with singlet oxygen in selected model systems. Free. Radic. Biol. Med. 2011, 50, 892-898. [CrossRef]

38. Augustine, J.; Troendle, E.P.; Barabas, P.; McAleese, C.A.; Friedel, T.; Stitt, A.W.; Curtis, T.M. The Role of Lipoxidation in the Pathogenesis of Diabetic Retinopathy. Front. Endocrinol. 2021, 11, 621938. [CrossRef] [PubMed] 
39. Kang, Q.; Yang, C. Oxidative stress and diabetic retinopathy: Molecular mechanisms, pathogenetic role and therapeutic implications. Redox Biol. 2020, 37, 101799. [CrossRef]

40. Sahajpal, N.S.; Goel, R.K.; Chaubey, A.; Aurora, R.; Jain, S.K. Pathological Perturbations in Diabetic Retinopathy: Hyperglycemia, AGEs, Oxidative Stress and Inflammatory Pathways. Curr. Protein Pept. Sci. 2019, 20, 92-110. [CrossRef]

41. Mas, E.; Woodman, R.; Burke, V.; Puddey, I.B.; Beilin, L.J.; Durand, T.; Mori, T.A. The omega-3 fatty acids EPA and DHA decrease plasma F2-isoprostanes: Results from two placebo-controlled interventions. Free. Radic. Res. 2010, 44, 983-990. [CrossRef]

42. Suzumura, A.; Terao, R.; Kaneko, H. Protective Effects and Molecular Signaling of n-3 Fatty Acids on Oxidative Stress and Inflammation in Retinal Diseases. Antioxidants 2020, 9, 920. [CrossRef] [PubMed]

43. Thota, R.; Acharya, S.H.; Garg, M.L. Curcumin and/or omega-3 polyunsaturated fatty acids supplementation reduces insulin resistance and blood lipids in individuals with high risk of type 2 diabetes: A randomised controlled trial. Lipids Health Dis. 2019, 18, 31. [CrossRef] [PubMed]

44. Abbott, K.; Burrows, T.; Acharya, S.; Thota, R.; Garg, M. DHA-enriched fish oil reduces insulin resistance in overweight and obese adults. Prostaglandins Leukot. Essent. Fat. Acids 2020, 159, 102154. [CrossRef] [PubMed]

45. Alsbirk, K.E.; Seland, J.H.; Assmus, J. Diabetic retinopathy and visual impairment in a Norwegian diabetic coast population with a high dietary intake of fish oils. An observational study. Acta Ophthalmol. 2021. [CrossRef] [PubMed]

46. Qian, F.; Korat, A.V.A.; Imamura, F.; Marklund, M.; Tintle, N.; Virtanen, J.K.; Zhou, X.; Bassett, J.K.; Lai, H.; Hirakawa, Y.; et al. n-3 Fatty Acid Biomarkers and Incident Type 2 Diabetes: An Individual Participant-Level Pooling Project of 20 Prospective Cohort Studies. Diabetes Care 2021, 44, 1133-1142. [CrossRef]

47. Jenkins, B.J.; Seyssel, K.; Chiu, S.; Pan, P.H.; Lin, S.Y.; Stanley, E.; Ament, Z.; West, J.A.; Summerhill, K.; Griffin, J.L.; et al. Odd Chain Fatty Acids; New Insights of the Relationship between the Gut Microbiota, Dietary Intake, Biosynthesis and Glucose Intolerance. Sci. Rep. 2017, 7, 44845. [CrossRef] [PubMed]

48. Weitkunat, K.; Schumann, S.; Nickel, D.; Hornemann, S.; Petzke, K.J.; Schulze, M.B.; Pfeiffer, A.F.H.; Klaus, S. Odd-chain fatty acids as a biomarker for dietary fiber intake: A novel pathway for endogenous production from propionate. Am. J. Clin. Nutr. 2017, 105, 1544-1551. [CrossRef]

49. Imamura, F.; Fretts, A.; Marklund, M.; Ardisson Korat, A.V.; Yang, W.S.; Lankinen, M.; Qureshi, W.; Helmer, C.; Chen, T.A.; Wong, K.; et al. Fatty Acid Biomarkers of Dairy Fat Consumption and Incidence of Type 2 Diabetes: A Pooled Analysis of Prospective Cohort Studies. PLoS Med. 2018, 15, e1002670. [CrossRef]

50. Saadatian-Elahi, M.; Slimani, N.; Chajès, V.; Jenab, M.; Goudable, J.; Biessy, C.; Ferrari, P.; Byrnes, G.; Autier, P.; Peeters, P.H.; et al. Plasma phospholipid fatty acid profiles and their association with food intakes: Results from a cross-sectional study within the European Prospective Investigation into Cancer and Nutrition. Am. J. Clin. Nutr. 2008, 89, 331-346. [CrossRef] [PubMed]

51. Santaren, I.D.; Watkins, S.M.; Liese, A.D.; Wagenknecht, L.E.; Rewers, M.J.; Haffner, S.M.; Lorenzo, C.; Hanley, A.J. Serum pentadecanoic acid (15:0), a short-term marker of dairy food intake, is inversely associated with incident type 2 diabetes and its underlying disorders. Am. J. Clin. Nutr. 2014, 100, 1532-1540. [CrossRef] [PubMed]

52. Chang, Y.-C.; Lin, C.-W.; Chang, Y.-S.; Chen, P.-H.; Li, C.-Y.; Wu, W.-C.; Kao, Y.-H. Monounsaturated oleic acid modulates autophagy flux and upregulates angiogenic factor production in human retinal pigment epithelial ARPE-19 cells. Life Sci. 2020, 259, 118391. [CrossRef]

53. Fang, I.-M.; Yang, C.-H.; Yang, C.-M.; Chen, M.-S. Comparative effects of fatty acids on proinflammatory gene cyclooxygenase 2 and inducible nitric oxide synthase expression in retinal pigment epithelial cells. Mol. Nutr. Food Res. 2009, 53, 739-750. [CrossRef]

54. Alcubierre, N.; Navarrete-Muñoz, E.M.; Rubinat, E.; Falguera, M.; Valls, J.; Traveset, A.; Vilanova, M.-B.; Marsal, J.R.; Hernández, M.; Granado-Casas, M.; et al. Association of low oleic acid intake with diabetic retinopathy in type 2 diabetic patients: A case-control study. Nutr. Metab. 2016, 13, 40. [CrossRef]

55. Vessby, B.; Tengblad, S.; Lithell, H. Insulin Sensitivity is Related to the Fatty Acid Composition of Serum Lipids and Skeletal Muscle Phospholipids in 70-Year-Old Men. Diabetologia 1994, 37, 1044-1050. [CrossRef] [PubMed]

56. Vessby, B. Dietary fat, fatty acid composition in plasma and the metabolic syndrome. Curr. Opin. Lipidol. 2003, 14, 15-19. [CrossRef]

57. Haug, A.; Høstmark, A.T.; Harstad, O.M. Bovine Milk in Human Nutrition-A Review. Lipids Health Dis. 2007, 6, 25. [CrossRef] [PubMed] 